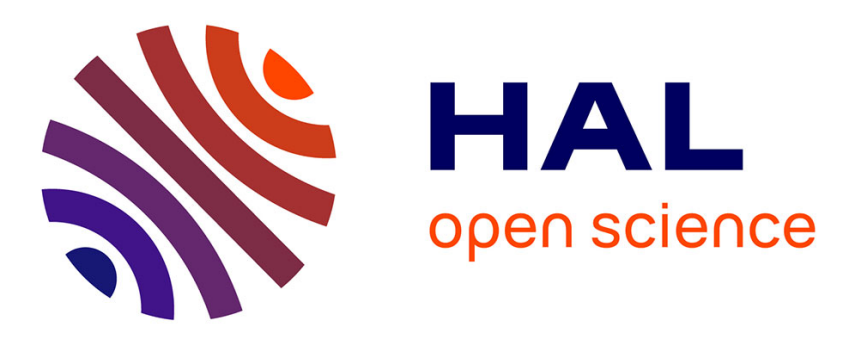

\title{
The crown of love: intimate relations and alcohol use in adolescence
}

\author{
Carmen S. Zwaluw, Ron H. J. Scholte, Ad A. Vermulst, Jan Buitelaar, \\ Robbert Jan Verkes, Rutger C. M. E. Engels
}

\section{- To cite this version:}

Carmen S. Zwaluw, Ron H. J. Scholte, Ad A. Vermulst, Jan Buitelaar, Robbert Jan Verkes, et al.. The crown of love: intimate relations and alcohol use in adolescence. European Child and Adolescent Psychiatry, 2009, 18 (7), pp.407-417. 10.1007/s00787-009-0748-6 . hal-00478101

\section{HAL Id: hal-00478101 \\ https://hal.science/hal-00478101}

Submitted on 30 Apr 2010

HAL is a multi-disciplinary open access archive for the deposit and dissemination of scientific research documents, whether they are published or not. The documents may come from teaching and research institutions in France or abroad, or from public or private research centers.
L'archive ouverte pluridisciplinaire HAL, est destinée au dépôt et à la diffusion de documents scientifiques de niveau recherche, publiés ou non, émanant des établissements d'enseignement et de recherche français ou étrangers, des laboratoires publics ou privés. 
Carmen S. van der Zwaluw

Ron H.J. Scholte

Ad A. Vermulst

Jan Buitelaar

Robbert Jan Verkes

Rutger C.M.E. Engels

\section{The crown of love: intimate relations and alcohol use in adolescence}

Received: 28 January 2008

Accepted: 12 December 2008

Published online: 5 February 2009
C.S. van der Zwaluw $(\bowtie) \cdot$ R.H.J. Scholte

A.A. Vermulst · R.C.M.E. Engels

Behavioural Science Institute

Radboud University Nijmegen

P.O. Box 9104

6500 HE Nijmegen, The Netherlands

Tel.: $+31-24 / 3612803$

Fax: +31-24/3612776

E-Mail: c.vanderzwaluw@bsi.ru.nl

J. Buitelaar · R.J. Verkes

Department of Psychiatry

Radboud University Nijmegen

Medical Centre

Nijmegen, The Netherlands
Abstract Background Remarkably, little attention has been paid to the role of intimate partners and their drinking behavior in relation to adolescent alcohol use. In the current study, we examined associations between adolescent alcohol use and romantic partners' drinking behavior. Methods A total of 428 families, consisting of both parents and two adolescents (aged 13.4 and 15.2 at Time 1) participated in a prospective study with four annual waves. Correlations and multivariate regressions were used to examine (1) similarity in drinking behaviors of adolescents and intimate partners, (2) whether alcohol use of partners prospectively predicts adolescent alcohol consumption, and (3) whether adolescents who consume alcohol select partners over time who show similar drinking behaviors. Results (1) Frequency of alcohol consumption of adolescents and of their romantic partners correlated significantly.
(2) Alcohol use of partners was not predictive of adolescent alcohol consumption over time, if previous levels of alcohol consumption were taken into account. (3) Adolescents acquired partners with similar drinking behaviors. Gender effects were found; adolescent girls, but not boys, were more likely to become involved with partners who also frequently consumed alcohol. Conclusions Regarding alcohol consumption, adolescents and their intimate partners were relatively similar in alcohol use. This resemblance is best explained by adolescents' selection of future partner on the basis of alcohol consumption. Less indication was found for influence effects, perhaps due to the transient nature of most adolescent romantic relationships.

Key words adolescent alcohol - romantic relationship partner

\section{Introduction}

In most Western societies, adolescence is an important period in life; one in which identities are formed and the capacity to form intimate relations is developed [17]. While children focus on relationships with parents and same-sex peers to fulfill their primary needs such as closeness and trust, adolescents shift their attention to peer groups and romantic partners. It is the period in which youngsters start to display interest in dating and sexual experiences [59], with romantic partners generally becoming a central aspect of their lives [20]. Adolescents spend a lot of time with 
their romantic partners, go out to bars and clubs together, and interact more with their partners than with parents or friends [33]. In addition, partners form an important source of support for adolescents [21].

Adolescence is also a period of experimenting with risk behaviors, such as using alcohol. Alcohol consumption has become quite common among youngsters in most Western societies. A Dutch nation-wide study showed that almost $90 \%$ of 12 to 15 -year-old adolescents had tried alcohol at least once, and that the frequency and quantity of alcohol consumption increased with age, until the age of 25 [43]. In addition, over half of Dutch adolescents (58\%) has consumed alcohol in the previous month [40] and 34\% reports binge drinking during two previous weeks [38]. In the search for social-environmental factors that may affect adolescent drinking, it was shown that both friends' and parents' drinking patterns are important in the initiation and persistence of adolescent alcohol use $[48,51,53]$. Since romantic relations are highly important in adolescents' lives [4] it seems likely that partners will affect adolescent alcohol use as well. Studies on the relationships between alcohol consumption of romantic partners and adolescent drinking behavior, however, are scarce, and a number of important issues have remained unaddressed.

To begin with, whether adolescents and their partners actually resemble each other in drinking behavior ${ }^{1}$ is unknown. Studies on married adult couples show that consumption patterns of substance use tend to be similar for partners (mate correlation: $[24,26,36,47,56]$ ). This resemblance in drinking behavior of adult partners could mainly stem from two processes: the direct influence of the partner's behavior (reciprocal spousal interaction effects), and the selection of a partner with similar phenotypic traits (assortative mating) ${ }^{2}$. Several studies have shown that once adults get married, they drink less alcohol than single or divorced persons [10, $45,52]$. These associations were found in adults, but may also hold for adolescents. Indeed, Engels and Knibbe [13] showed that once male, but not female, adolescents become involved in a steady relationship, they will drink less than males without a partner, indicating that involvement in a relationship decreases alcohol use of adults and (male) adolescents. These studies did not inform us, however, on the effects of the partner's alcohol use on adolescent drinking. Studies examining reciprocal influence effects between partners' alcohol consumption revealed that partners also affect

\footnotetext{
${ }^{1}$ Resemblance and similarity are in this context considered relative concepts, since females consume systematically less alcohol than males.

${ }^{2}$ By mentioning these two processes, it is not intended to be exhaustive in potential processes underlying mate similarity. Other approaches have been mentioned, such as the social homogamy process [47] and the evolutionary psychology paradigm [5].
}

each other's alcohol use through their own drinking behaviors [12, 34, 35]. In addition, assortative mating ("like marries like") seems to be an etiological factor for adult spouse similarities in alcohol dependence $[1,25$, $32,37]$. For example, Agrawal and colleagues [1] found that adult women who regularly used alcohol were more likely to marry men with similar behavioral patterns. Regarding adolescents, it is conceivable that they also select their intimate partners on the basis of common values, personality dynamics, and common life orientations [16, 31]. The consumption of alcohol and the activities that go along with drinking, such as spending time in 'wet' places (i.e. bars, pubs, clubs) may be part of these common life orientations on which adolescents select their partners. Given the finding that more than half $(58 \%)$ of the young adults under 30 years meet their partner while they are going out or while visiting friends [6], it seems plausible that adolescents select partners with similar drinking habits. However, research examining influence or selection effects among adolescents and their romantic partners is lacking.

From the existing literature it is not quite clear whether influence or selection effects differ for men and women. Some have proposed that problem behavior in girls is more frequently determined by and dependent on their partner's problem behavior than vice versa [31]. Studies on adults showed that the direction of effects in drinking patterns was often from husband to wife $[12,34]$, while others did not find differences between men and women [25]. As men drink consistently more alcohol than women [43] we will examine, on an explorative basis due to the paucity of results in adolescents, the role of sex in associations between alcohol use of adolescents and their partners.

In the current study we will examine (1) whether alcohol consumption of adolescents is associated with drinking behaviors of their romantic partners, (2) whether alcohol consumption of the partner affects adolescent drinking behavior over time, and (3) whether adolescents select their partners (partly) based on alcohol consumption. We expect that (1) adolescents and partners will be highly similar in their drinking behaviors and that (2) alcohol consumption of the partner will affect adolescent alcohol use over time. We also hypothesize that (3) alcohol consumption patterns of the potential partner will be a selection criterion for adolescents.

\section{Method}

\section{Procedure}

In 2002-2003 (T1) 428 Dutch families were recruited to participate in a longitudinal survey with annual waves (for details on sample selection see $[27,55]$ ). 
Via municipality registers throughout the Netherlands 5,602 families with at least two adolescents in the age range of 13-16 years were approached. A total of 885 families agreed to participate. Families were included if the parents were married or living together, and if all family members were biologically related. If there were more than two adolescents between 13 and 16 years old in one family, the family members themselves decided who was going to participate in the study. Families with adolescent twins, or mentally or physically disabled adolescents were excluded. In addition, we aimed at an equal number of sibling dyads (boy-boy, girl-girl, boy-girl, girlboy), which resulted in a total of 428 participating families. Over time, numbers of dropout families were low, with 416 (97\%), 404 (94\%), and 347 (81\%) families participating in waves two (T2), three (T3), and four (T4) respectively. Attrition analyses were conducted to examine whether adolescents who participated in all four waves differed from those who were not involved in the second, third or fourth wave. $T$ tests showed no significant differences $(P>0.05)$ in alcohol use, sex, or age between the younger adolescent dropouts $(N=88)$ and participants $(N=340)$. Regarding the older adolescents, no significant differences were found in sex or age between dropouts $(N=86)$ and respondents $(N=342)$. However, older adolescent dropouts consumed significantly more often alcohol on T1 than respondents $(t(426)=-2.04, P=0.04)$.

In the physical presence of a trained interviewer, all family members separately filled in the questionnaires at home. The interviewer was instructed to not explain questions or actually interview the family members, but made sure that the participants did not consult each other and that questions and answers were not discussed during the questionnaire completion. Each family received 30 Euros per wave when every family member had completed the questionnaire. Approval on data collection was obtained from the Central Committee on Research Involving Human Subjects in the Netherlands.

\section{Sample characteristics}

The families consisted of father, mother, and two adolescents. Regarding sex of the adolescents we obtained an equal distribution; $53 \%$ of the younger siblings ${ }^{3}$, and $47 \%$ of the older siblings were girls at $\mathrm{T} 1$. Mean age was 13.4 ( $\mathrm{SD}=0.50$; ranging from 14 to 17 years) for the younger and $15.2(\mathrm{SD}=0.60$; ranging

\footnotetext{
${ }^{3}$ To describe the younger participating adolescent of the family the terms 'younger adolescent' and 'younger sibling' will be used interchangeably throughout this article. In a similar vein 'older adolescent' and 'older sibling' will both be used to denote the older participating sibling of the family.
}

from 13 to 15 years) for the older adolescents at $\mathrm{T} 1$. Fathers' ages ranged between 37 and $62(M=46.2$, $\mathrm{SD}=4.00)$, and mothers were between 35 and 56 years old $(M=43.8, \mathrm{SD}=3.57)$. The majority of participants were of Dutch (Caucasian) origin (>95\%). At T1, a third of the adolescents followed lower general secondary education, a third followed higher general secondary education, and a third followed collegepreparatory secondary education. The different levels of the Dutch secondary school system are comparable with the different tracks within a middle class public high school in the USA.

\section{Measures}

Adolescents', siblings', and parental alcohol use were measured by self-reports with identical measures at each wave. Adolescents also reported whether they were involved in a romantic relationship and on alcohol consumption of their partner and best friend.

\section{Alcohol use}

Adolescents were asked how often they had consumed alcohol in the past 4 weeks [13]. Frequency of alcohol use was measured on a 6-point scale (1 'did not drink any alcohol in the past 4 weeks', 2 'drank alcohol at 1 to 3 days in the past 4 weeks, 3 'drank alcohol at 1 to 2 days per week, 4 'drank alcohol at 3-4 days per week', 5 'drank alcohol at 5-6 days per week, 6 'drank alcohol every day in the past 4 weeks'). As such, frequency of adolescent alcohol was self-reported and measured from the perspective of the adolescent.

\section{Romantic partner}

Adolescent involvement in a romantic relationship was assessed with the question: 'At this moment, are you going steady with someone, or are you having a steady relationship?' which could be answered with 1 'no', or 2 'yes.' Interpretations of 'going steady' or 'having a steady relationship' were left to the adolescent's perspective as there was no additional clarification given.

\section{Partner and best friend's alcohol use}

Both younger and older adolescents answered the question on the frequency of their partner's and their best friend's alcohol consumption in the past 4 weeks. Answers on a 6-point scale ranged from 1 has not been drinking' to 6 'every day' [13].

\section{Parents' and siblings' alcohol use}

Because of the full-family design of our study we were able to use self-reports of the siblings and of the 
parents on their alcohol use. Mothers, fathers, and siblings reported individually on the item measuring the frequency of alcohol use in the past 4 weeks on a 6-point scale. Answer categories ranged from 1 have not been drinking' to 6 'every day'.

\section{Adolescent problem drinking}

Adolescent problem drinking was measured with the Rutgers' alcohol problem index (RAPI; [57]) which assesses problematic situations that are related to alcohol use. The scale consists of 18 items. Examples of items are: 'You went to school or to work while you were still under the influence of alcohol', 'You were unable to do your homework because you had consumed alcohol', and 'You acted unkind or got involved in a fight because you had consumed alcohol'. Responses were given on a 5-point scale ranging from 1 'never' to 5 'very often'. Over the three waves Cronbach's alphas were between 0.72 and 0.87 for both younger and older adolescents.

\section{Statistical analyses}

Descriptive statistics and Pearson correlation coefficients were determined with SPSS-14. With General Linear Modeling repeated measures it was tested whether adolescent alcohol use differed significantly over time. Since involvement in a romantic relationship was a dichotomous variable, Cochran's Q was used as a non-parametric alternative for the repeated measures analyses [19]. Because the adolescents' partners were not necessarily the same partners over time, we could not examine whether partner's frequency of drinking changed over time. First, because the younger and older siblings differ on average almost 2 years in age $\left(M_{\text {age }}\right.$ younger adolescents $=13.4$, $M_{\text {age older adolescents }}=15.2$ ), which puts them into two different developmental stages (early adolescence and middle adolescence; see [50]), the analyses were carried out for younger and older adolescents separately, in SPSS (see below). Second, the two groups were merged into one group of adolescents. Because the two siblings are part of the same family their data are statistically dependent, or nested. Therefore, the analyses for the merged group of adolescents were carried out in Mplus, in which it is possible to control for dependence of the data $($ TYPE $=$ COMPLEX procedure, in combination with the CLUSTER command: [39]). In this procedure all adolescents were collapsed into one group. Standard errors of the parameter estimates were corrected for dependency, resulting in unbiased estimates (see e.g., [11]). No model fit indices were obtained as we tested a saturated path model.

(1) Pearson correlations were used to examine cross-sectional and bivariate correspondence in drinking behaviors between adolescents and partners. With hierarchical multiple regression analyses for the separate groups of adolescents and path analyses for the total group of adolescents we tested whether (2) partner's alcohol use predicted adolescent's drinking behavior over time. To control for alcohol use in the social environment of the adolescent and to make sure that partner effects could be solely attributed to alcohol use of the partner, alcohol consumption of parents, sibling, and best friend were also included in the first step of the regression analyses and the path analyses. The interaction between alcohol use of the partner and sex of the adolescent $(1=$ boy, $2=$ girl $)$ was entered in the second step. Interaction terms were computed as the product of the partner's alcohol use and sex of the adolescent after centering both variables to prevent multicollinearity [30]. Additionally, to examine whether comparable developments would occur in more problematic, abusive adolescent alcohol use similar regression analyses and path analyses were carried out with adolescent problem drinking as dependent variable. (3) To examine whether adolescent alcohol use resulted in involvement with an alcohol consuming intimate partner over time, we created a separate group of adolescents who did not have a partner at $\mathrm{T} 1$, but were involved in a romantic relationship 1 year later. A similar procedure was applied for subsequent waves. With hierarchical multiple regression analyses, we examined whether adolescents selected their partners based on similarity in alcohol consumption over time (see e.g., [54] for similar procedures). As such it was tested whether adolescents who were not involved with a partner at T1 acquired a partner at T2 (partly) based on similarities in their alcohol consumption, which implies selection [54]. This procedure was repeated for waves 2, 3, and 4. As such, whether adolescent alcohol use resulted in involvement with a partner who drinks alcohol was analyzed year by year. We again controlled for alcohol use in the social environment of the adolescent by including parental, sibling's and best friend's alcohol use in the hierarchical multiple regression analyses and in the path analyses. The interactions between sex of the adolescent and adolescent alcohol use was entered in the second step. Similar analyses were carried out for adolescent problem drinking.

\section{Results}

\section{Descriptives}

Descriptives on frequencies of both adolescent alcohol consumption and partner's alcohol use are shown 
Table 1 Descriptives on frequency of alcohol use of adolescents and their romantic partners

\begin{tabular}{|c|c|c|c|c|c|c|c|c|}
\hline & \multicolumn{2}{|l|}{$\mathrm{T} 1$} & \multicolumn{2}{|l|}{ T2 } & \multicolumn{2}{|l|}{ T3 } & \multicolumn{2}{|l|}{ T4 } \\
\hline & M & SD & M & SD & M & SD & M & SD \\
\hline Older adolescent & $1.99^{\mathrm{a}}$ & 1.05 & $2.29^{b}$ & 1.02 & $2.42^{c}$ & 0.99 & $2.78^{\mathrm{d}}$ & 1.12 \\
\hline Younger adolescent & $1.32^{\mathrm{a}}$ & 0.99 & $1.67^{b}$ & 0.98 & $1.96^{\mathrm{c}}$ & 1.02 & $2.58^{d}$ & 1.16 \\
\hline Partner older adolescent & 2.42 & 1.07 & 2.31 & 0.84 & 2.41 & 0.86 & 2.74 & 1.07 \\
\hline $\begin{array}{l}\text { Partner younger } \\
\text { adolescent }\end{array}$ & 1.98 & 0.93 & 2.35 & 0.94 & 2.47 & 0.96 & 2.62 & 1.08 \\
\hline
\end{tabular}

Frequency of adolescent alcohol use increased significantly over time, with means in the same row that do not share superscripts $(a, b, c, d)$ being significantly different $(P<0.01)$

in Table 1. Descriptives on the distribution of the response categories of frequency of alcohol consumption are depicted in Table 2. Both older and younger adolescents increased their frequency of alcohol consumption significantly over time, as was tested with general linear modeling (for the older adolescent $F(3,322)=46.09, \quad P<0.001, \quad$ Partial $\eta^{2}=0.30$; for the younger adolescent: $F(3,320)=$ 95.26, $P<0.001$, Partial $\left.\eta^{2}=0.47\right)$. Within subjects contrasts showed significant differences between $\mathrm{T} 1$ and $\mathrm{T} 2, \mathrm{~T} 2$ and $\mathrm{T} 3$, and $\mathrm{T} 3$ and $\mathrm{T} 4$ for both older and younger siblings $(P<0.01)$. Because adolescents' partners at T1 were not necessarily the same partners at subsequent waves, we could not examine whether the partner's frequency of drinking changed over time. Older adolescents reported significantly more alcohol than younger adolescents at all three time points (T1, T2, T3: $P<0.001$; T4: $P<0.05$ ).

At T1, 60 younger adolescents (14\%) had partners. Romantic involvement for the younger adolescents increased significantly over time, with 63 adolescents $(15 \%)$ at T2, 96 adolescents $(22 \%)$ at T3, and 110 adolescents $(26 \%)$ at $\mathrm{T} 4$ reporting to be romantically involved (Cochran's $Q(309,3)=74.45, P<0.001)$. Regarding the older adolescents, 89 participants (21\%) were involved in a steady relationship at $\mathrm{T} 1$. The number of romances increased significantly over time, to $118(28 \%)$ at $\mathrm{T} 2,145(34 \%)$ at $\mathrm{T} 3$, and $156(36 \%)$ at T4 (Cochran's $Q(312,3)=65.32, P<0.001)$.

\section{Correlations}

Pearson correlations were used to assess relative cross-sectional similarity ${ }^{1}$ in drinking behaviors between adolescents and intimate partners (hypothesis 1) and are shown in Table 3. It was found that the frequencies of both older and younger adolescents' alcohol use were strongly associated with the drinking frequencies of their partners (for the older adolescents: $0.41 \leq r \leq 0.44, P<0.001$; for the younger adolescents: $.44 \leq r \leq 0.50, P<0.001)$. Also for the total group of adolescents, alcohol use was significantly correlated with their partners' alcohol use $(0.44 \leq r \leq 0.48, P<0.001)$. Since the number of adolescents with a romantic partner fluctuated over time, correlations for the separate groups in Table 3 were based on variable group sizes.

\section{Partners' alcohol use as prospective predictor for adolescents' alcohol use and problem drinking}

With the exception of the correlations between partners' alcohol use at T3 and alcohol use of the older adolescents at T4 $(r=0.11, n . s$, , see Table 3$)$, bivariate correlations between alcohol use of the partner and adolescent alcohol use at a subsequent wave were positive and significant $(0.28 \leq r \leq 0.34, P<0.05)$. This was also the case in the total group of adolescents $(0.27 \leq r \leq 0.48, P<0.001)$, indicating positive relations between partners' and adolescents' alcohol use over time (hypothesis 2).

To further test whether frequency of alcohol use of the partner predicted younger and older adolescent alcohol use over time, we conducted hierarchical multivariate regression analyses in SPSS and path analyses in Mplus. Results are depicted in Table 4 and show that in general both for the separate younger and older adolescent groups as well as for the total group of adolescents, alcohol use of the partner did not significantly predict adolescent alcohol use over time, if prior levels of adolescent alcohol use were taken into account. Alcohol use of both parents was in

Table 2 Distribution of frequency of alcohol use in the past 4 weeks

\begin{tabular}{|c|c|c|c|c|c|c|c|c|}
\hline & \multicolumn{4}{|c|}{ Younger adolescents } & \multicolumn{4}{|c|}{ Older adolescents } \\
\hline & $\mathrm{T} 1$ & $\mathrm{~T} 2$ & T3 & T4 & $\mathrm{T} 1$ & $\mathrm{~T} 2$ & $\mathrm{~T} 3$ & T4 \\
\hline 1. Did not drink any alcohol & $241(56.3 \%)$ & 159 (37.1\%) & $114(26.6 \%)$ & $46(10.7 \%)$ & $121(28.3 \%)$ & $71(16.6 \%)$ & $55(12.9 \%)$ & $41(9.6 \%)$ \\
\hline 2. Drank alcohol at 1 to 3 days & $139(20.6 \%)$ & $178(41.6 \%)$ & $169(39.5 \%)$ & $110(25.7 \%)$ & $157(36.7 \%)$ & $158(36.9 \%)$ & $132(30.8 \%)$ & $88(20.6 \%)$ \\
\hline 3. Drank alcohol at $1-2$ days & $36(8.4 \%)$ & 65 (15.2\%) & $103(24.1 \%)$ & $122(28.5 \%)$ & $123(28.7 \%)$ & 145 (33.9\%) & $169(39.5 \%)$ & $121(28.3 \%)$ \\
\hline 4. Drank alcohol at 3-4 days & 8 (1.9\%) & $11(2.6 \%)$ & $9(2.1 \%)$ & $42(9.8 \%)$ & $22(5.1 \%)$ & $35(8.2 \%)$ & 37 (8.6\%) & 73 (17.1\%) \\
\hline 5. Drank alcohol at 5-6 days & $1(0.2 \%)$ & $2(0.5 \%)$ & $6(1.4 \%)$ & $11(2.6 \%)$ & $3(0.7 \%)$ & $2(0.5 \%)$ & $7(1.7 \%)$ & 14 (3.3\%) \\
\hline 6. Drank alcohol every day & - & - & - & $6(1.4 \%)$ & $2(0.5 \%)$ & - & - & $1(0.2 \%)$ \\
\hline
\end{tabular}

Percentages do not add up to one hundred because of missing values 
Table 3 Correlations between frequency of adolescents' and partners' alcohol use

\begin{tabular}{|c|c|c|c|c|c|c|c|c|}
\hline & Adolescent T1 & Partner T1 & Adolescent T2 & Partner T2 & Adolescent T3 & Partner T3 & Adolescent T4 & Partner T4 \\
\hline Adolescent T1 & & $0.44^{* * *}$ & $0.51^{* * *}$ & $0.33^{*}$ & $0.35^{* * *}$ & $0.31^{* *}$ & $0.14^{* *}$ & 0.01 \\
\hline Partner T1 & $0.41^{* * *}$ & & $0.34^{* *}$ & $0.56^{* *}$ & $0.32^{*}$ & $0.59^{* *}$ & -0.03 & 0.31 \\
\hline Adolescent T2 & $0.39^{* * *}$ & $0.32^{* *}$ & & $0.50^{* * *}$ & $0.44^{* * *}$ & $0.21^{*}$ & $0.19^{* * *}$ & $0.20^{*}$ \\
\hline Partner T2 & $0.33^{* * *}$ & $0.47^{* *}$ & $0.41^{* * *}$ & & $0.28^{*}$ & $0.50^{* *}$ & 0.01 & -0.02 \\
\hline Adolescent T3 & $0.35^{* * *}$ & $0.32^{* *}$ & $0.54^{* * *}$ & $0.30^{* *}$ & & $0.45^{* * *}$ & $0.36^{* * *}$ & $0.31^{* *}$ \\
\hline Partner T3 & 0.11 & 0.27 & $0.35^{* * *}$ & $0.50^{* * *}$ & $0.43^{* * *}$ & & $0.28^{* *}$ & $0.35^{* *}$ \\
\hline Adolescent T4 & $0.16^{* *}$ & 0.04 & $0.31^{* * *}$ & 0.15 & $0.36^{* * *}$ & 0.11 & & $0.48^{* * *}$ \\
\hline $\begin{array}{l}\text { Partner T4 } \\
\text { Adolescent T1 }\end{array}$ & 0.11 & $0.31^{*}$ & $0.17^{*}$ & $0.46^{* * *}$ & $0.29^{* * *}$ & $0.41^{* * *}$ & $0.44^{* * *}$ & \\
\hline Partner T1 & $0.47^{* * *}$ & & & & & & & \\
\hline Adolescent T2 & $0.52^{* * *}$ & $0.32^{* * *}$ & & & & & & \\
\hline Partner T2 & $0.34^{* * *}$ & $0.55^{* * *}$ & $0.45^{* * *}$ & & & & & \\
\hline Adolescent T3 & $0.44^{* * *}$ & $0.30^{* * *}$ & $0.54^{* * *}$ & $0.27^{* * *}$ & & & & \\
\hline Partner T3 & $0.20^{* *}$ & $0.31^{* *}$ & $0.30^{* * *}$ & $0.62^{* * *}$ & $0.44^{* * *}$ & & & \\
\hline Adolescent T4 & $0.31^{* * *}$ & $0.22^{* *}$ & $0.34^{* * *}$ & 0.10 & $0.50^{* * *}$ & $0.48^{* * *}$ & & \\
\hline Partner T4 & 0.10 & $0.39 * * *$ & $0.18^{* *}$ & $0.29 * * *$ & $0.32^{* * *}$ & $0.37^{* * *}$ & $0.48^{* * *}$ & \\
\hline
\end{tabular}

T1 Time 1, T2 Time 2, T3 Time 3, T4 Time 4. Correlations based on the reports of the older adolescents $(44 \leq N \leq 428)$ are below the diagonal in the top section. Correlations based on the reports of the younger adolescents $(21 \leq N \leq 425)$ are above the diagonal in the top section. Correlations based on the total group of adolescents are depicted in the lower section

${ }^{*} P<0.05 ;{ }^{* *} P<0.01,{ }^{* * *} P<0.001$

general also not prospectively associated with adolescent alcohol use. Alcohol use of the best friend was marginally significantly related to later adolescent alcohol use for the older adolescent and the total group of adolescents from $\mathrm{T} 1$ to $\mathrm{T} 2$, and for the younger adolescents and the total group of adolescents from T3 to T4. For the older adolescents alcohol use of their younger sibling was significantly associated with later adolescent alcohol consumption from T2 to T3. In turn, the older siblings affected the younger adolescents' alcohol use from T1 to T2. The interactions between alcohol use of the partner and sex of the adolescent were in general not significantly associated with adolescent alcohol use.

To examine whether results would differ for adolescents who reported signs of problem drinking, similar regression and path analyses were carried out. However, we used adolescent problem drinking instead of adolescent frequency of alcohol consumption as dependent variable. Results did not show significant associations between partner's alcohol use and later adolescent problem drinking, neither in the separate groups of adolescents nor in the total group of adolescents $(-0.10<\beta<0.05$, n.s. $)$. Only for the younger adolescents the interaction between partners' drinking and sex of the adolescent was significant ( $\beta=-0.28, P<0.01)$, indicating that boys, but not girls with heavy drinking partners showed higher levels of problem drinking.

\section{Acquiring an alcohol-using partner}

Significant bivariate correlations between adolescents' and partners' alcohol use 1 year later indicated posi-
Table 4 Prospective relations between partner's alcohol consumption and adolescent alcohol use: influence processes

\begin{tabular}{lccc}
\hline & \multicolumn{3}{c}{ Alcohol use adolescent } \\
\cline { 2 - 4 } & $\mathrm{T} 1 \rightarrow \mathrm{T} 2$ & $\mathrm{~T} 2 \rightarrow \mathrm{T} 3$ & $\mathrm{~T} 3 \rightarrow \mathrm{T} 3$ \\
\hline Older adolescent & $N=80$ & $N=99$ & $N=98$ \\
Alcohol use adolescent & $0.32^{*}$ & $0.51^{* * *}$ & $0.45^{* * *}$ \\
Alcohol use partner & -0.01 & 0.15 & 0.02 \\
Alcohol use mother & 0.04 & 0.06 & 0.02 \\
Alcohol use father & 0.18 & -0.04 & 0.12 \\
Alcohol best friend & $0.26^{\dagger}$ & -0.10 & 0.06 \\
Alcohol use younger sibling & -0.06 & $0.31^{* * *}$ & 0.10 \\
Sex & $-0.26^{*}$ & -0.10 & -0.12 \\
Sex $\times$ Alcohol use partner & $0.18^{\dagger}$ & 0.10 & -0.09 \\
Younger adolescent & $N=57$ & $N=54$ & $N=74$ \\
Alcohol use adolescent & 0.25 & $0.34^{*}$ & $0.38^{* *}$ \\
Alcohol use partner & 0.24 & 0.20 & 0.04 \\
Alcohol use mother & -0.09 & 0.09 & 0.08 \\
Alcohol use father & $0.23^{\dagger}$ & 0.10 & 0.10 \\
Alcohol best friend & -0.11 & -0.10 & $0.22^{\dagger}$ \\
Alcohol use older sibling & $0.25^{\dagger}$ & -0.03 & 0.01 \\
Sex & 0.16 & -0.21 & -0.06 \\
Sex $\times$ Alcohol use partner & -0.14 & -0.20 & 0.05 \\
Total group of adolescents & $N=856$ & $N=856$ & $N=856$ \\
Alcohol use adolescent & $0.39^{* * *}$ & $0.42^{* * *}$ & $0.40^{* * *}$ \\
Alcohol use partner & 0.09 & $0.18^{\dagger}$ & -0.02 \\
Alcohol use mother & 0.06 & $0.10^{* *}$ & 0.01 \\
Alcohol use father & 0.05 & 0.01 & $0.09^{*}$ \\
Alcohol best friend & $0.11^{\dagger}$ & 0.02 & $0.14^{* *}$ \\
Sex & $-0.08^{*}$ & $-0.15^{* *}$ & $-0.11^{*}$ \\
Sex $\times$ Alcohol use partner & 0.00 & -0.12 & -0.21 \\
\hline & & & \\
\hline
\end{tabular}

Values in table represent standardized regression coefficients (beta's). Interaction terms were entered in step two of the regression analyses ${ }^{\dagger} p<0.10 ;{ }^{*} p<0.05 ; * * P<0.01 ; * * * P<0.001$

tive relations between adolescent drinking and partner's alcohol use over time $(0.21 \leq r \leq 0.35, P<0.05$, see Table 3). 
Table 5 Prospective relations between adolescent alcohol use and later partner's alcohol use: selection processes

\begin{tabular}{lccc}
\hline & \multicolumn{3}{l}{ Alcohol use partner } \\
\cline { 2 - 4 } & $\mathrm{T} 1 \rightarrow \mathrm{T} 2$ & $\mathrm{~T} 2 \rightarrow \mathrm{T} 2$ & $\mathrm{~T} 3 \rightarrow \mathrm{T} 3$ \\
\hline Older adolescent & $N=85$ & $N=89$ & $N=83$ \\
Alcohol use adolescent & $0.27^{*}$ & $0.32^{* *}$ & $0.33^{*}$ \\
Alcohol use mother & $0.20^{\dagger}$ & -0.12 & 0.03 \\
Alcohol use father & 0.13 & 0.01 & -0.07 \\
Alcohol use best friend & $0.19^{\dagger}$ & 0.17 & -0.06 \\
Alcohol use younger sibling & 0.16 & $0.19^{\dagger}$ & 0.12 \\
Sex & 0.15 & $0.22^{*}$ & $0.33^{* *}$ \\
Sex $\times$ Alcohol use adolescent & -0.00 & $0.18^{\dagger}$ & $0.26^{*}$ \\
Younger adolescent & $N=55$ & $N=80$ & $N=69$ \\
Alcohol use adolescent & $0.29^{*}$ & 0.01 & 0.15 \\
Alcohol use mother & -0.00 & 0.02 & 0.02 \\
Alcohol use father & 0.06 & $0.25^{*}$ & 0.16 \\
Alcohol use best friend & 0.13 & 0.16 & $0.29^{*}$ \\
Alcohol use older sibling & 0.04 & 0.07 & -0.02 \\
Sex & $0.48^{* * *}$ & $0.36^{* *}$ & $0.42^{* * *}$ \\
Sex $\times$ Alcohol use adolescent & -0.01 & -0.02 & 0.20 \\
Total group of adolescents & $N=149$ & $N=181$ & $N=241$ \\
Alcohol use adolescent & 0.17 & $0.25^{* *}$ & $0.26^{* *}$ \\
Alcohol use mother & 0.05 & 0.06 & $0.10^{\dagger}$ \\
Alcohol use father & 0.00 & 0.03 & 0.03 \\
Alcohol use best friend & $0.51^{* * *}$ & $0.41^{* * *}$ & $0.34^{* * *}$ \\
Sex & $0.27^{* * *}$ & $0.42^{* * *}$ & $0.36^{* * *}$ \\
Sex $\times$ Alcohol use adolescent & 0.27 & 0.31 & $0.57^{*}$ \\
\hline Val & & & \\
\hline
\end{tabular}

Values represent standardized regression coefficients (beta's). Interaction terms were entered in step two of the regression analyses

${ }^{\dagger} p<0.10 ;{ }^{*} P<0.05$; ${ }^{* *} P<0.01$

Frequency of alcohol use of the older adolescent significantly predicted frequency of alcohol use of the older adolescent's partner over time, indicating that older adolescents may have acquired their partners partly on drinking behavior (see Table 5). This result was also found for younger adolescents, but only between $\mathrm{T} 1$ and $\mathrm{T} 2$. For the total group of adolescents, frequency of adolescent alcohol use significantly predicted partners' alcohol consumption between T2 and T3, and between T3 and T4. Parental alcohol use and siblings' alcohol use were in general not significantly associated with later alcohol use of the partner. Best friend's alcohol consumption was significantly associated with partner's alcohol use for the older adolescents from T1 to T2, and for the younger adolescents from $\mathrm{T} 3$ to $\mathrm{T} 4$. In the total group of adolescents, best friend's drinking was significantly associated with partner's alcohol consumption over time at all waves.

Sex was also a significant predictor for partners' alcohol use, with girls being more likely to select an alcohol-consuming partner than boys. Interaction effects between adolescent sex and adolescent alcohol use on partner's alcohol use were significant for the older adolescents from $\mathrm{T} 2$ to $\mathrm{T} 3$, and from $\mathrm{T} 3$ to $\mathrm{T} 4$, and for the total group of adolescents from T3 to T4, but not for the younger adolescents at all time points and for the older adolescents from $\mathrm{T} 1$ to $\mathrm{T} 2$. The significant interaction effects indicated that girls, but not boys, who frequently drank alcohol became involved with partners who also frequently consumed alcohol.

Again we carried out similar regression and path analyses, but with adolescent problem drinking as a predictor to examine whether results would differ for individuals who scored high on problem drinking. Results did not show significant associations between adolescent problem drinking and partner's alcohol use over time neither in the separate groups of adolescents nor in the total group $(-0.02<\beta<0.17$, n.s.). For the total group and for the younger adolescents, the interaction between partners' drinking and sex of the adolescent was significant $(\beta=0.16$, $P<0.10$ and $\beta=0.25, P<0.05$ respectively), indicating that girls high on problem drinking were more likely to become involved with a heavy drinking partner than boys.

\section{Additional analyses: Involvement in a romantic relationship}

Because several studies showed that adults and adolescents with steady relationships drink less alcohol than single or divorced persons [10, 13, 45, 52], we also tested whether involvement in romantic relationships was associated with adolescent alcohol use over time. Results are depicted in Appendix 1, and show that involvement with a romantic partner was not prospectively associated with alcohol use, in neither older or younger adolescents, nor in the total group of adolescents. Sex was a significant predictor, with boys consuming alcohol significantly more frequent than girls. Further, the interactions between sex of the adolescent and partner involvement were not significantly associated with adolescent alcohol use over time.

\section{Discussion}

The current study examined the relationships between adolescent alcohol use and romantic partners' alcohol consumption. The first main finding showed that, despite the stable systematic differences in alcohol use between Dutch boys and girls [43], adolescents and their intimate partners were relatively similar in their frequency of alcohol use. This is consistent with the literature on adults reporting relative similarities in drinking between spouses (e.g., [26, 32, 56]). The resemblance of romantic partners in drinking behavior could basically stem from two processes; 
reciprocal influence processes or selection processes (assortative mating).

Our analyses found less support for the influence hypothesis than for the selection hypothesis. Partners' alcohol use did not affect later adolescent alcohol use, if prior adolescent alcohol use was taken into account. This may be explained by the fact that most adolescent relationships are rather short-lived $[8,18,58]$, implicating that if influence effects regarding alcohol use do take place between adolescents, a yearly interval might be too long to measure these effects. Zimmer-Gembeck [58] demonstrated that in her sample of American 18-year-old females the average length of a steady relation was 8.6 months. In addition, Canadian 15year-olds had romantic partners for on average 4 months [18]. Another explanation refers to the fact that adolescents often consume alcohol in peer groups. It might be that the partner is not part of the group in which the adolescent regularly drinks alcohol, thus, adolescents and partners do not frequently consume alcohol in each other's company. It may also be that, in case the partner is part of the peer group, the influence of the partner merges with the group effects. Overbeek and coworkers [42] showed with observational data that only group effects (i.e., average group levels of alcohol consumption) and not best friend's alcohol use explained young adults' drinking behavior. This group effect may also explain the non-significant and marginal effects that respectively parents and best friends exerted on adolescent alcohol use. It is important to note that although partners' alcohol use did not prospectively predict adolescents' alcohol consumption, there might be subtle influence effects that were not measured. Perhaps most influence processes do not carry on over a long period of time, but occur more directly, for example if one directly models (imitates) the alcohol consumption of a drinking partner [3]. Observation and diary studies may be suitable to assess influence or modeling effects in drinking situations directly (see e.g., [46]).

Our third main finding provided support for the hypothesis that adolescents acquired their partners partly based on similarities in drinking behavior. This finding concurs with the adult literature, showing that assortative mating significantly augmented spousal similarity [1, 32, 37]. Grant and colleagues [25] even showed that assortative mating amplified spouse similarity, while spousal interaction influences decreased similarity if assortative mating was taken into account. Our study demonstrates that assortative mating already occurs at a young age in adolescence and drinking behaviors play a role in the processes of acquiring a partner. In addition, this process will also be context-based, since $80 \%$ of adolescent alcohol consumption takes place outdoors in wet settings such as bars, clubs or parties [14], where there is a reasonable chance they will also meet a partner. We also found a small interaction effect with sex, indicating that girls who drank more often than other girls, chose partners who consumed alcohol more frequently. This effect was not found for boys. A speculative explanation is that for boys it is more socially accepted than for girls to consume large amounts of alcohol. It might even make boys look 'tough', while girls might not be considered 'charming' when drinking large amounts of alcohol, deeming them less attractive (e.g., [29]).

Adolescent's problem drinking was not significantly associated with their partner's alcohol use over time. Also, partners' alcohol use did not significantly influence adolescents' problem drinking over time. The lack of effects might be due to the low prevalence of problem drinking in our sample. However, romantic partner, family, and peer behaviors, such as their alcohol consumption, may be especially important with regard to excessive alcohol use (e.g., [7, 49]). As such, future studies should focus on a subgroup of heavy drinking adolescents/ young adults who might acquire and become affected by a heavy drinking partner, making them at risk for alcohol abuse later in life.

Alcohol use of both mothers and fathers was in general not prospectively related to adolescent drinking. Best friend's alcohol consumption was associated with alcohol use of both adolescents and partners, but only if they were around 15-16 years, implicating that in this specific group of adolescents with a romantic partner, friends' behavior is most important at this age [21].

\section{Limitations}

Our study is the first to examine associations between adolescent alcohol use and drinking behaviors of the romantic partners with a four-wave longitudinal design. However, there are some limitations that need to be addressed. First, although we used self-reports of adolescents and parental alcohol use, assessments of drinking by best friends and partners were based on the adolescents' perceptions. It has been questioned whether adolescents can accurately report on their friends' alcohol use [2]. Recent studies have shown that adolescents are fairly accurate in estimating their best friend's alcohol use [44] and smoking [28]. Because adolescents interact even more with intimate partners than with friends [33], the assessments of their partners' alcohol use might be even more precise than the estimations of their friends' alcohol consumption. Similarly, we only used adolescent self-reports to assess adolescent alcohol use, which may cause aspects related to social desirability, such as over- or underreporting, to play a role [41]. Others 
have suggested the use of collateral (parent) reports to validate the accuracy of adolescents' self-reports [9]. However, a recent study has shown that parents are not very accurate in estimating their children's alcohol consumption, especially when these children are still young and in the early phase of adolescence [15]. In addition, we tried to minimize reporting bias by ensuring anonymity and making sure that the questionnaires were filled out individually. Second, adolescents who are involved with a romantic partner form a highly specific sample, which implies that the results found in this study cannot be generalized to a population level. For example, female adolescents who start dating earlier than others may form a specific sub-sample of 'early maturers' [22], a group that may also start earlier with alcohol consumption [23]. A third limitation is the possibility that a third variable explains both dating behavior and alcohol use. It may be that adolescents who are early maturers, who score high on sensation seeking, or who differ in other ways on personality variables, may start early both with dating and drinking alcohol on a relatively frequent basis. Future studies with larger sample sizes should examine the relationships between adolescent and romantic partner's alcohol use and personality factors. Fourth, the family members in our study were all biologically related, the parents were married or living together, and the vast majority of families were of Dutch origin. Step-families, single parent families, and non-Caucasian families were not represented, limiting the generalizability to the Dutch population as a whole. Regarding drinking behavior, however, levels of frequency of alcohol use in our sample were comparable to those in the Dutch adolescent population [40], enhancing possibilities to generalize our results to Dutch adolescents.

Taking these limitations into account, this study is one of the first to disentangle associations between alcohol use of romantic partners and adolescent alcohol use in a longitudinal design. Results indicate that partner's alcohol use is not associated with adolescent alcohol use over time, but adolescents acquire their romantic partners based on similarities in their drinking. This implies that partner selection processes, which have earlier been demonstrated in adults (see e.g., [25]), already occur at rather young ages, i.e. during adolescence and young adulthood.

\section{Appendix 1}

Prospective relationships between involvement with a romantic partner and adolescent alcohol use

\begin{tabular}{lccc}
\hline & Alcohol use adolescent & & \\
\cline { 2 - 4 } & $\mathrm{T} 1 \rightarrow \mathrm{T} 2$ & $\mathrm{~T} 2 \rightarrow \mathrm{T} 3$ & $\mathrm{~T} 3 \rightarrow \mathrm{T} 4$ \\
\hline Older adolescent & $N=409$ & $N=395$ & $N=320$ \\
Alcohol use adolescent & $0.48^{* * *}$ & $0.60^{* * *}$ & $0.56^{* * *}$ \\
Partner involvement & 0.03 & 0.00 & 0.07 \\
Sex & $-0.12^{* *}$ & $-0.09^{*}$ & $-0.09^{\dagger}$ \\
Sex $\times$ Partner involvement & -0.07 & 0.02 & -0.02 \\
Younger adolescent & $N=410$ & $N=396$ & $N=312$ \\
Alcohol use adolescent & $0.55^{* * *}$ & $0.56^{* * *}$ & $0.50^{* * *}$ \\
Partner involvement & 0.03 & -0.01 & -0.06 \\
Sex & 0.02 & -0.01 & $-0.14^{* *}$ \\
Sex $\times$ Partner involvement & $0.10^{*}$ & -0.05 & 0.01 \\
Total group of adolescents & $N=856$ & $N=856$ & $N=856$ \\
Alcohol use adolescent & $0.51^{* * *}$ & $0.53^{* * *}$ & $0.48^{* * *}$ \\
Partner involvement & 0.05 & 0.01 & 0.01 \\
Sex & $-0.06^{*}$ & $-0.08^{*}$ & $-0.13^{* *}$ \\
Sex $\times$ Partner involvement & 0.02 & -0.07 & -0.08 \\
\hline
\end{tabular}

Values represent standardized regression coefficients (beta's). Interaction terms were entered in step two of the regression analyses

${ }^{\dagger} P<0.10 ;{ }^{*} P<0.05 ;{ }^{* *} P<0.01 ;{ }^{* *} P<0.001$

\section{References}

1. Agrawal A, Heath AC, Grant JD, Pergadia ML, Statham DJ, Bucholz KK, Martin NG, Madden PAF (2006)

Assortative mating for cigarette smok- ing and for alcohol consumption in female Australian twins and their spouses. Behav Genet 36:553-566
2. Bauman KE, Ennett ST (1996) On the importance of peer influence for adolescent drug use: commonly neglected considerations. Addiction 91:185-198 
3. Bot SM, Engels RCME, Knibbe RA, Meeus WHJ (2007) Pastime in a pub: observations of young adults' activities and alcohol consumption. Addict Behav 32:491-504

4. Bouchey HA, Furman W (2003) Dating and romantic experiences in adolescence. In: Adams GR, Berzonsky MD (eds) Blackwell handbook of adolescence. Blackwell, Oxford, pp 313-329

5. Buss DM, Schmitt DP (1993) Sexual strategies theory: an evolutionary perspective on human mating. Psychol Rev 100:204-232

6. CBS Statistics Netherlands, Onderzoek Gezinsvorming [Research on Family Formation]. (2003) Retrieved 31 Oct 2007 from http://www.cbs.nl

7. Chassin L, Curran PJ, Hussong AM, Colder CR (1996) The relation of parent alcoholism to adolescent substance use: a longitudinal study. J Abnorm Psychol 105:70-80

8. Connolly JA, Johnson MA (1996) Adolescents' romantic relationships and the structure and quality of their close interpersonal ties. Pers Relatsh 3:185-195

9. Connors GJ, Maisto SA (2003) Drinking reports from collateral individuals. Addiction 98(Suppl 2):21-29

10. Curran PJ, Muthén BO, Harford TC (1998) The influence of changes in marital status on developmental trajectories of alcohol use in young adults. J Stud Alcohol 59:647-658

11. De Leeuw RN, Scholte RHJ, Harakeh Z, Van Leeuw JFJ, Engels RCME (2008) Parental smoking-specific communication, adolescents' smoking behavior and friendship selection. J Youth Adol 37:1229-1241

12. Demers A, Bisson J, Palluy J (1999) Wives' convergence with their husbands' alcohol use: social conditions as mediators. J Stud Alcohol 60:368-377

13. Engels RCME, Knibbe RA (2000) Alcohol use and intimate relationships in adolescence: when love comes to town. Addict Behav 25:435-439

14. Engels RCME, Knibbe RA, Drop MJ (1999) Visiting public drinking places: an explorative study into the functions of pub-going for late adolescents. Subst Use Misuse 34:1261-1280

15. Engels RCME, Van der Vorst H, Dekovic M, Meeus W (2007) Correspondence in collateral and self-reports on alcohol consumption: a within family analysis. Addict Behav 32:1016-1030

16. Ennett ST, Bauman KE (1994) The contribution of influence and selection to adolescent peer group homogeneity: the case of adolescent cigarette smoking. J Pers Soc Psychol 67:653-663

17. Erikson EH (1968) Identity: youth and crisis. Norton, New York
18. Feiring C (1996) Concepts of romance in 15-year-old adolescents. J Res Adolesc 6:181-200

19. Field A (2005) Discovering statistics using SPSS. Sage, London

20. Furman W (2002) The emerging field of adolescent romantic relationships. Curr Dir Psychol Sci 11:177-180

21. Furman W, Buhrmester D (1992) Age and sex differences in perceptions of networks of personal relationships. Child Dev 63:103-115

22. Gargiulo J, Attie I, Brooks-Gun J, Warren MP (1987) Girls' dating behavior as a function of social context and maturation. Dev Psychol 23:730737

23. Ge X, Jin R, Natsuaki MN, Gibbons FX, Brody GH, Cutrona CE, Simons RL (2006) Pubertal maturation and early substance use risks among African American children. Psychol Addict Behav 20:404-414

24. Graham K, Braun K (1999) Concordance of use of alcohol and other substances among older adult couples. Addict Behav 24:839-856

25. Grant JD, Heath AC, Bucholz KK, Madden PAF, Agrawal A, Statham DJ, Martin NGM (2007) Spousal concordance for alcohol dependence: evidence for assortative mating or spousal interaction effects? Alcohol Clin Exp Res 31:717-728

26. Hall RL, Hesselbrock VM, Stabenau JR (1983) Familial distributions of alcohol use: II. Assortative mating of alcoholic probands. Behav Genet 13:373-382

27. Harakeh Z, Scholte RHJ, De Vries H, Engels RCME (2005) Parental rules and communication: their association with adolescent smoking. Addiction 100:862-870

28. Harakeh Z, Engels RCME, Vermulst AA, De Vries H, Scholte RHJ (2007) The influence of best friends and siblings on adolescent smoking: a longitudinal study. Psychol Health 22:269289

29. Huselid RF, Cooper ML (1992) Gender roles as mediators of sex differences in adolescent alcohol use and abuse. J Health Soc Behav 33:348-362

30. Jaccard J, Wan CK, Turrisi R (1990) The detection and interpretation of interaction effects between continuous variables in multiple regression. Multivar Behav Res 25:467-478

31. Jaccard J, Blanton H, Dodge T (2005) Peer influences on risk behavior: an analysis of the effects of a close friend. Dev Psychol 41:135-147

32. Kendler KS, Neale MC, Heath AC, Kessler RC, Eaves LJ (1994) A twinfamily study of alcoholism in women. Am J Psychiatry 151:707-715
33. Laurens B, Williams VA (1997) Perceptions of interdependence and closeness in family and peer relationships among adolescents with and without romantic partners. In: Shulman S, Collins WA (eds) Romantic relationships in adolescence: developmental perspectives. Jossey-Bass, San Francisco, pp 3-20

34. Leonard KE, Das Eiden R (1999) Husband's and wife's drinking: unilateral or bilateral influences among newlyweds in a general population sample. J Stud Alcohol Suppl 13:130-138

35. Leonard KE, Mudar P (2004) Husbands' influence on wives' drinking: testing a relationship motivation model in the early years of marriage. Psychol Addict Behav 18:340-349

36. Low N, Cui L, Merikangas KR (2007) Spousal concordance for substance use and anxiety disorders. J Psychiatr Res 41:942-951

37. Maes HHM, Neale MC, Kendler KS, Hewitt JK, Silberg JL, Foley DL, Meyer JM, Rutter M, Simonoff E, Pickles A, Eaves LJ (1998) Assortative mating for major psychiatric diagnoses in two population-based samples. Psychol Med 28:1389-1401

38. Monshouwer K, Smit F, De Zwart WM, Spruit I, Van Ameijden EJC (2003) Progress from a first drink to first intoxication: age of onset, time-windows and risk factors in a Dutch national sample of secondary school students. J Subst Use 8:155-163

39. Muthén LK, Muthén BO (1998-2006) Mplus user's guide, 4th edn. Muthén \& Muthén, Los Angeles

40. National Drugs Monitor (NDM) (2004). Jaarrapport 2004 [Year report 2004]. Trimbos Instituut Utrecht

41. Offer D, Kaiz M, Howard KI, Bennett ES (2000) The altering of reported experiences. J Am Acad Child Adolesc Psychiatry 39:735-742

42. Overbeek G, Bot SM, Sentse M, Meeus WHJ, Knibbe RA, Engels RCME (2009) Where it's at! The role of best friends and peer group members in young adults' alcohol use. J Res Adolesc (in press)

43. Poelen EAP, Scholte RHJ, Engels RCME, Boomsma DI, Willemsen G (2005) Prevalence and trends of alcohol use and misuse among adolescents and young adults in the Netherlands from 1993 to 2000. Drug Alcohol Depend 79:413-421

44. Poelen EAP, Engels RCME, Van der Vorst H, Scholte RHJ, Vermulst AA (2007) Best friends and alcohol consumption in adolescence: a within family analysis. Drug Alcohol Depend $88: 163-173$ 
45. Prescott CA, Kendler KS (2001) Associations between marital status and alcohol consumption in a longitudinal study of female twins. J Stud Alcohol 62:589-604

46. Quigley BM, Collins RL (1999) The modeling of alcohol consumption: a meta-analytic review. J Stud Alcohol 60:90-98

47. Reynolds CA, Barlow T, Pedersen NL (2006) Alcohol, tobacco, caffeine use: spouse similarity processes. Behav Genet 36:201-215

48. Sher KJ (1991) Children of alcoholics: a critical appraisal of theory and research. The University of Chicago Press, Chicago

49. Sher KJ, Wallitzer KS, Wood PK, Brent EE (1991) Characteristics of children of alcoholics: putative risk factors, substance use and abuse, and psychopathology. J Abnorm Psychol 100:427448

50. Steinberg L (1993) Adolescence, 3rd edn. McGraw-Hill, New York
51. Swadi H (1999) Individual risk factors for adolescent substance use. Drug Alcohol Depend 55:209-224

52. Temple MT, Fillmore KM, Hartka E, Johnstone B, Leino EV, Motoyoshi M (1991) A meta-analysis of change in marital and employment status as predictors of alcohol consumption on a typical occasion. Br J Addict 86:12691281

53. Urberg KA, Değirmencioğlu SM, Pilgrim C (1997) Close friend and group influence on adolescent cigarette smoking and alcohol use. Dev Psychol 33:834-844

54. Urberg KA, Luo Q, Pilgrim C, Degimenciogly SM (2003) A two-stage model of peer influence in adolescent substance use: individual and relationship-specific differences in susceptibility to influence. Addict Behav 28:12431256

55. Van der Vorst H, Engels RCME, Meeus W, Dekovic M, Van Leeuwe J (2005) The role of alcohol-specific socialization in adolescents' drinking behavior. Addiction 100:1464-1476
56. Vanyukov MM, Neale MC, Moss HB, Tarter RE (1996) Mating assortment and the liability to substance use. Drug Alcohol Depend 42:1-10

57. White HR, Labouvie EW (2000) Longitudinal trends in problem drinking as measured by the Rutgers alcohol problem index. Paper presented at the 23rd annual scientific meeting of the Research Society on alcoholism, Denver

58. Zimmer-Gembeck MJ (1999) Stability, change and individual differences in involvement with friends and romantic partners among adolescent females. J Youth Adolesc 28:419-438

59. Zimmer-Gembeck MJ (2002) The development of romantic relationships and adaptations in the system of peer relationships. J Adolesc Health 31:216225 